Nunt. Antiquus, Belo Horizonte, v. 17, n. 1, p. 183-196, 2021

\title{
Tradução comentada da carta VII.9 de Plínio, o Jovem
}

\section{A commented translation of the letter VII.9 of Pliny the Younger}

\author{
Renato Cardoso Corgosinho \\ Pontifícia Universidade Católica de Minas Gerais (PUC Minas), Belo Horizonte, \\ Minas Gerais/Brasil \\ renatoccor@yahoo.com.br \\ https://orcid.org/0000-0003-2523-4092
}

Resumo: Apresentamos aqui uma tradução comentada da carta VII.9 (nona carta do sétimo livro) do Epistolário de Plínio, o Jovem, que a nosso ver se configura como uma versão reduzida do capítulo V, livro X, da Instituição Oratória de Quintiliano. Os comentários, portanto, atêm-se aos aspectos retóricos presentes na referida carta.

Palavras-chave: retórica antiga; retórica romana; Plínio, o Jovem.

Abstract: We present a commented translation of the letter VII.9 (ninth letter of the tenth book) from Pliny the Younger's Epistulae, witch in our view is configured as a reduced version of the chapter V (book X) of the Institutes of Oratory by Quintilian. Our comments therefore take into account the rhetorical aspects in the said letter.

Keywords: ancient rhetoric; Roman rhetoric; Pliny the Younger.

\section{Introdução}

Plínio, o Jovem, enquadra-se em uma tradição retórica que se pode dizer grega na essência, mas romana nos contornos e nuances culturais, sociais e políticos. Nos primórdios, a eloquência exercitada em Roma, sendo uma conveniente adaptação da que se desenvolvera na Grécia, procurava atender tão somente a uma necessidade utilitária de persuasão ou celebração na esfera pública (DOMINIK, 2017). 
Nesse sentido, a oratória, que se pode considerar a parte prática da eloquência, procurava forjar nos indivíduos a instrumentalidade necessária para a construção de discursos que pudessem produzir, em público, os efeitos de convencimento ou refutação desejados, o que decorria naturalmente da solidificação gradual do establishment estatal.

A implementação da ars bene dicendi em terras do Lácio, entretanto, não ocorreria sem percalços, uma vez que o tão propalado espírito pragmático dos romanos teria fundamentado (não obstante demonstrarem estes grande facilidade de adaptação e incorporação de outras culturas) significativa desconfiança, seguida de resistência e intolerância, contra a cada vez mais influente retórica grega, ${ }^{1}$ o que viria culminar com o decreto de expulsão dos retores gregos na primeira metade do séc. II a.C. ${ }^{2}$ A partir daí, o embate entre o pragmatismo romano e o tecnicismo grego escancarou aquilo que passaria a ser uma das principais características da oratória praticada em Roma, ou seja, sua função política. Suas temáticas tenderiam, por conseguinte, a refletir o zelo pela ética, a moral e a tradição como baluartes do Estado, e a criticar tudo o que não estivesse em consonância com esses princípios.

Cícero traçou no Brutus um panorama dessas origens, apresentando e avaliando fatos e personalidades que em sua visão tiveram relevância na história da eloquência latina, dentre as quais, Ápio Cláudio Cego (administrador), no séc. III a.C., que teria logrado dissuadir um senado extremamente vacilante de concluir a paz com o rei Pirro da Macedônia (Brutus, 55); no séc. II a.C., Catão, o Censor, que a despeito de sua aversão a tudo que fosse grego, incluindo a retórica, distinguiu-se como insigne orador, ${ }^{3}$ Papírio Carbão (tribuno e

${ }^{1}$ Um dos mais ferrenhos críticos da influência grega em Roma foi Catão, o Censor, que teria dito (cf. Plínio, o Velho, 29.14, tradução nossa): "Quando esse povo nos der sua cultura, corromperá tudo." (Quandoque ista gens suas litteras dabit, omnia conrumpet). ${ }^{2}$ De acordo com Dominik (2017, p.161, tradução nossa), essa expulsão teria sido motivada não apenas pelo sentimento anti-helênico (personificado na figura influente de Catão), exacerbado pela sofisticação e eficácia das técnicas gregas em comparação com a simplicidade rústica da retórica romana, mas também pela "preocupação da elite senatorial com o uso da retórica por outsiders que estavam começando a forjar carreiras que eram percebidas como uma ameaça à ordem política estabelecida." (the concern felt by the senatorial elite over the use of rethoric by outsiders who were begining to forge careers that were perceived as a threat to the established political order).

3 Cícero devotava-lhe grande admiração, a ponto de dizer: "Bons deuses, mas que homem! Omito o cidadão, o senador ou o general, pois o que avaliamos aqui é o orador. Quem mais austero do que ele no elogio, mais acerbo no vitupério, mais arguto nas 
cônsul), ${ }^{4}$ além dos antigos mestres de Cícero, Marco Antônio e Crasso, considerados pelo ilustre discípulo como oradores de primeira ordem, comparáveis a Demóstenes e Hipérides (Brutus, 138).

Na centúria seguinte, veremos o próprio arpinate, reconhecidamente o maior de todos os oradores romanos, que, na esteira sobretudo de Catão, o Censor, revolucionaria a eloquência latina, convencido de que a técnica não poderia estar desvinculada da moral, da ética e dos bons costumes. Para ele, o orador deveria ser um sapiens, intrinsecamente ligado aos destinos do Estado e da sociedade em que vivia. Essa visão seria um desdobramento do princípio, que se atribui a Catão, do uir bonus peritus dicendi, segundo o qual o orador perfeito é aquele que não apenas domina a arte de falar, mas também reúne em si as qualidades morais necessárias para que possa atuar em prol de sua comunidade. Nesse sentido, Cícero (apud PEREIRA, 1990, p. 195), em tom poético e naturalmente eloquente, sintetiza a relevância que atribui ao orador e à oratória:

$\mathrm{Na}$ verdade, para já não falar da utilidade da oratória, que é soberana em toda a cidade que viva em paz e com liberdade, é tal a fascinação da habilidade oratória que nada de mais aprazível pode ser percebido por ouvidos ou mentes humanas. Quem pode descobrir canto mais doce do que um discurso equilibrado? [...] Um ator mais agradável ao imitar a verdade do que um orador que a apoia? Que há de mais delicado do que a abundância e a agudeza das frases? [...] Que plenitude superior do discurso recheado de toda a espécie de conhecimentos? Não há assunto que não seja pertença do orador, desde que se exponha com elegância e gravidade. A ele pertence, ao dar parecer sobre

opiniões, mais meticuloso na instrução e na exposição? Seus discursos, mais de cento e cinquenta os que encontrei e li até agora, são repletos de palavras e temas brilhantes." (Brutus, 65, tradução nossa) (At quem virum, di boni! Mitto civem aut senatorem aut imperatorem-oratorem enim hoc loco quaerimus; quis illo gravior in laudando acerbior in vituperando, in sententiis argutior in docendo edisserendoque subtilior? Refertae sunt orationes amplius centum quinquaginta, quas quidem adhuc invenerim et legerim, et verbis et rebus illustribus.)

4 Cícero nos fornece o testemunho de seu amigo Lúcio Gélio, que tendo conhecido e convivido com Carbão, caracterizava-o como "orador melodioso, fluente e bastante mordaz, e ao mesmo tempo veemente, muito agradável e espirituoso [...] era também zeloso e diligente, e costumava se empenhar muito nos estudos e exercícios." (Brutus, 105 , tradução nossa) (canorum oratorem et volubilem et satis acrem atque eundem et vehementem et valde dulcem et perfacetum [...] industrium etiam et diligentem et in exercitationibus commentationibusque multum operae solitum esse ponere). 
os mais altos interesses, dar uma sentença exposta com dignidade; a ele, incitar um povo debilitado e moderar um desvairado; é a mesma arte que leva o crime à perdição e a inocência à salvação. Quem pode exortar à virtude com mais ardor, afastar dos vícios com mais acrimônia, censurar a desonestidade com mais aspereza, louvar os bons com mais elegância? (De oratore, II. 8-9).

O orador perfeito, portanto, é um êmulo da verdade, que se utiliza da palavra equilibrada, das sutilezas e possibilidades da frase bem construída e agradavelmente proferida, para convencer, orientar e pacificar, que orna seus discursos com os mais diversos temas advindos de uma vasta bagagem de conhecimentos, o sujeito fadado a alcançar uma proeminência indiscutível na sociedade e nas questões cívicas, um verdadeiro homem de Estado, capaz de abrandar as querelas políticas, um defensor irredutível das virtudes e dos bons costumes, um opositor ferrenho ao crime e à desonestidade.

Se a oratória é a faceta prática da eloquência, a retórica procurará sistematizar a técnica, estabelecendo um corpo de regras e princípios que visam fornecer ao orador ferramentas para o incremento e a especialização da linguagem, para a arquitetura e a construção do discurso, em suma, os conhecimentos e o direcionamento mais adequados a uma formação técnica, teórica e humanística robusta. Cícero, devido aos diversos tratados que escreveu, ${ }^{5}$ em que estrutura uma scientia bene dicendi, também neste campo alcançará a primazia, passando a ser o grande paradigma do retórico romano.

Quintiliano (séc. I d.C.), herdeiro e continuador da obra retórica de Cícero, não poupa elogios, em sua Instituição Oratória, à figura do mestre que, em sua opinião, deveria ser o padrão a ser seguido por professores e discípulos:

$\mathrm{Na}$ verdade, os oradores e particularmente a eloquência latina podem ombrear-se com os autores ou com a oratória dos gregos. Sob esse aspecto, eu confrontaria Cícero com qualquer um deles. [...] Destarte, merecidamente foi dito pelos homens de seu tempo que ele reinava nos tribunais, e entre os pósteros de fato se fixou que Cícero não designasse

${ }_{5}$ Sobre a invenção (De inventione), Sobre o orador (De oratore), Bruto (Brutus), O orador (Orator) e Sobre o melhor gênero de oradores (De optimo genere oratorum). 
apenas o nome de um homem, mas o fosse da própria oratória. Por isso, fixemos nele nossos olhos, que ele se torne nosso modelo; e quem quer que seja seu fiel admirador saiba que com isso já fez bastante progresso. ${ }^{6}(\mathrm{X} .1,105,112)$.

Pode-se considerar a obra magna (em 12 livros) de Quintiliano como um verdadeiro tratado pedagógico de eloquência, que aborda todas as nuances da formação oratória, desde o berço até o final da carreira do orador adulto. Aí repousaria a peculiaridade de Quintiliano em relação aos retores que o antecederam (inclusive Cícero) ou aos que lhe eram contemporâneos: ele gestou um projeto educacional de formação retórica ampla e completa (VASCONCELOS, 2002) que abarcava todas as fases etárias do indivíduo, a começar pela primeira idade, diferentemente de seus pares, que contemplavam apenas o orador já formado ou em formação. O princípio basilar de sua pedagogia se assentava na moral e na ética aliadas ao conhecimento técnico. De nada adiantaria esse conhecimento sem qualidades de caráter, pois "caso a força da oratória venha a insuflar a maldade, nada é mais pernicioso que a eloquência nos assuntos públicos e privados"7 (XII.1.1). Nesse sentido, o lema vir bonus peritus dicendi se configura como o pilar de todo o ensino retórico, que deve tutelar os candidatos a oradores, em parceria com suas famílias, desde a infância, para incutir-lhes os valores que se exigem de homens destinados a sustentar as rédeas da sociedade e do Estado. Assim,

[...] visamos a formar um homem não só proeminente por seus dons naturais, mas que também demonstre, profundamente enraizadas na mente, tantas qualidades belíssimas e, por fim, dedicado aos assuntos humanos, como nunca se viu, singular e perfeito sob todos os aspectos, pensando sempre o ótimo e expressando-se do melhor modo possível. $^{8}$ (XII, I, 25).

\footnotetext{
${ }^{6}$ Oratores vero vel praecipue Latinam eloquentiam parem facere Graecae possint. Nam Ciceronem cuicunque eorum fortiter opposuerim. [...] Quare non immerito ab hominibus aetatis suae regnare in iudiciis dictus est, apud posteros vero id consecutus, ut Cicero iam non hominis nomen, sed eloquentiae habeatur. Hunc itgur spectemus, hoc propositum nobis sit exemplum, ille se profecisse sciat, cui Cicero valde placebit. 7 Si vis illa dicendi malitiam instruxerit, nihil sit publicis privatisque rebus perniciosius eloquentia.

8 Virum cum ingenii natura praestantem tum vero tot pulcherrimas artes penitus mente complexum, datum tandem rebus humanis, qualem ulla antea vetustas cognoverit,
} 
Plínio, o Jovem, ${ }^{9}$ como já aventamos, é herdeiro de uma tradição retórica cujo ápice é Cícero, mas que ganha contornos novos e inovadores com Quintiliano. Embora não tenha produzido obras exclusivas sobre o tema, Plínio, que fora discípulo deste último (cf. Ep. II.14, 9), deixa explícita, em algumas cartas (v.g. VI.32 e VII.9), sua reverência ao mestre. Seu Epistolário compreende 368 cartas, divididas em X livros, abarcando um período temporal que começa no ano 96 (ou 97) e se encerra no ano 109 (110 ou 111). A dedução desse intervalo só se torna possível pela análise criteriosa das informações concernentes a determinados contextos históricos e sociais em que esteve inserido nosso missivista, e que foram por ele veiculadas no corpo de sua obra, uma vez que não se encontram neste referências contundentes a datas. Haveria, por outro lado, uma ordem cronológica entre os livros, ${ }^{10}$ mas não entre as cartas de cada livro, ${ }_{11}^{11}$ que apresentam, ademais, grande diversidade temática (varietas). Além disso, algumas características presentes nas epístolas de Plínio podem ser indícios de que ele não as escreveu com o intuito principal de enviá-las a seus destinatários, mas sim de publicá-las. Vê-se, dessa forma, na referida ausência de datas, bem como de subscrições e de pedidos de resposta, e no número significativo de destinatários (perto de 105), uma patente artificialidade de composição, o que reforçaria,

singularem perfectumque undique, optima sentientem optimeque dicentem.

9 Plínio, o Jovem (lat. Caius Plinius Caecilius Secundus): Escritor latino (nasceu em Como em 61 ou 62 d. C., morreu por volta de 114 d. C.), filho de L. Cecílio Cilão e de Plínia, irmã de Plínio, o Velho. Foi discípulo de Quintiliano, amigo de filósofos como Eufrates e Musônio Rufo. Advogado, cônsul no ano 100, legado propretor na Bitínia em 111 e 112. Escreveu várias obras, mas nos restam apenas o Epistolário em 10 livros e o Panegírico a Trajano. Plínio é o típico representante do diletantismo poético e literário de seu tempo; de gênio brilhante e versátil, cultura sólida e sentimentos honestos, literato de estilo, mas frequentemente artificioso; espírito sensível, porém conformista. Passava facilmente de um gênero literário a outro; gostava de alternar os ócios poéticos com a prática forense, fazendo a defesa dos inocentes e oprimidos. Tendo vivido em meio à sociedade civil de seu tempo, retratou em suas cartas não só seu ânimo e seus costumes, mas também os hábitos daquela sociedade em todas as suas caraterísticas. A esse respeito, o epistolário pliniano, além do valor literário, tem também valor histórico e psicológico.

${ }^{10} \mathrm{Cf}$. Mommsen, 1873.

${ }^{11}$ Assim o declara o próprio autor na primeira carta do primeiro livro, informando que ao compilar suas missivas não obedeceu a uma ordem cronológica (collegi non servato temporis ordine), mas aleatória (ut quacque in manus venerat). 
para boa parte dos críticos, a ideia de que Plínio destinara suas epístolas, desde a concepção, a serem publicadas (GÓMEZ, 1997). ${ }^{12}$

Das 368 constantes do Epistolário, 26 são admoestatórias (SHERWIN-WHITE, 1985), o que lhes confere caráter eminentemente didático, já que sempre comportam algum tipo de advertência, aconselhamento ou censura a seus destinatários. Dentre elas está a carta VII.9, na qual o remetente nos apresenta uma série sintetizada (e sistematizada) de exercícios que considera imprescindíveis para que seu interlocutor/destinatário desenvolva ou aprofunde habilidades oratórias, principalmente as relativas a leitura e escrita. Essa carta, na opinião de Whitton (2019), seria uma espécie de Instituição Oratória resumida. Nela, a referência à obra do mestre Quintiliano é evidente e, portanto, seu caráter emulativo torna-se uma de suas mais destacadas características.

O destinatário da epístola é Fusco (Gnaeus Pedanius Fuscus Salinator), que é mencionado outras cinco vezes no epistolário de Plínio (VI.11; VI.26; VII.9; IX.36; IX.40). Pelos dados sobre esse personagem recolhidos nas referidas passagens, depreende-se sua elevada condição social. ${ }^{13}$ Teria sido um patrício ${ }^{14} \mathrm{com}$ seus vinte e poucos anos, atuante nos tribunais e com chance real de ocupar uma vaga no senado romano, além de um devoto exemplar do nosso orador consular Plínio (WHITTON, 2019).

A carta VII.9 seria uma resposta a um pedido de Fusco para que Plínio o aconselhasse sobre a melhor forma de estudar (studere) durante o recesso (secessus), provavelmente da corte ou do senado. Estamos então diante de uma interlocução entre integrantes da rica aristocracia romana, oradores já formados nas escolas de retórica (o que não impede que um demande ao outro conselhos para aperfeiçoamento de suas habilidades), com experiência nas causas forenses e destacada influência social e política.

\footnotetext{
${ }^{12}$ Poder-se-ia objetar que o contexto apresentado na carta I.1, em que Plínio deixa claro que fora instado pelo interlocutor a reunir e publicar as cartas que escrevera com maior esmero, demonstra não haver ineditismo (ou originalidade) da matéria textual, e que, portanto, o epistolário seria de fato uma compilação de missivas que já haviam sido enviadas em algum momento a seus destinatários. O que se coloca em contraposição (ou aditamento) como hipótese plausível é que Plínio, na verdade, só tenha dado suas cartas à publicação após criteriosos processos de revisão e reelaboração.

${ }^{13}$ Fusco se casou com a sobrinha do futuro imperador Adriano (cf. Ep. VI.26).

${ }^{14}$ Cf. Ep. VI.11.
} 


\section{Texto latino ${ }^{15}$}

\section{Plinius Fusco suo s.}

1 Quaeris quemadmodum in secessu, quo iam diu frueris, putem te studere oportere. 2 Vtile in primis, et multi praeceperunt, uel ex Graeco in Latinum uel ex Latino uertere in Graecum; quo genere exercitationis proprietas splendorque uerborum, copia figurarum, uis explicandi, praeterea imitatione optimorum similia inueniendi facultas paratur. Simul quae legentem fefellissent transferentem fugere non possunt. Intellegentia ex hoc et iudicium acquiritur. 3 Nihil offuerit quae legeris hactenus, ut rem argumentumque teneas, quasi aemulum scribere lectisque conferre ac sedulo pensitare quid tu, quid ille commodius. Magna gratulatio, si non nulla tu, magnus pudor, si cuncta ille melius. Licebit interdum et notissima eligere et certare cum electis. 4 Audax haec, non tamen improba, quia secreta contentio; quamquam multos uidemus eius modi certamina sibi cum multa laude sumpsisse, quosque subsequi satis habebant, dum non desperant, antecessisse. 5 Poteris et quae dixeris post obliuionem retractare, multa retinere, plura transire, alia interscribere, alia rescribere. 6 Laboriosum istud et taedio plenum, sed difficultate ipsa fructuosum, recalescere ex integro et resumere impetum fractum omissumque, postremo noua velut membra peracto corpori intexere nec tamen priora turbare.

7 Scio nunc tibi esse praecipuum studium orandi, sed non ideo semper pugnacem hunc et quasi bellatorium stilum suaserim. Vt enim terrae uariis mutatisque seminibus, ita ingenia nostra nunc hac nunc illa meditatione recoluntur. 8 Volo interdum aliquem ex historia locum apprendas, uolo epistulam diligentius scribas. Nam saepe in oratione quoque non historica modo, sed prope poetica descriptionum necessitas incidit, et pressus sermo purusque ex epistulis petitur. 9 Fas est et carmine remitti, non dico continuo et longo (id enim perfici nisi in otio non potest), sed hoc arguto et breui, quod apte quantas libet occupationes curasque distinguit. 10 Lusus uocantur; sed hi lusus non minorem interdum gloriam quam seria consequuntur; atque adeo (cur enim te ad uersus non uersibus adhorter?)

${ }^{15} \mathrm{O}$ texto latino que utilizamos é o editado pela Les Belles Lettres (2002). 


\section{1 ut laus est cerae, mollis cedensque sequatur si doctos digitos iussaque fiat opus et nunc informet Martem castamue Mineruam, nunc Venerem effingat, nunc Veneris puerum, utque sacri fontes non sola incendia sistunt, saepe etiam flores uernaque prata iuuant, sic hominum ingenium flecti ducique per artes non rigidas docta mobilitate decet.}

12 Itaque summi oratores, summi etiam uiri sic se aut exercebant aut delectabant, immo delectabant exercebantque, 13 nam mirum est ut his opusculis animus intendatur, remittatur. Recipiunt enim amores, odia, iras, misericordiam, urbanitatem, omnia denique quae in uita atque etiam in foro causisque uersantur. 14 Inest his quoque eadem quae aliis carminibus utilitas, quod metri necessitate deuincti soluta oratione laetamur et quod facilius esse comparatio ostendit, libentius scribimus.

15 Habes plura etiam fortasse quam requirebas, unum tamen omisi; non enim dixi quae legenda arbitrarer; quamquam dixi, cum dicerem quae scribenda. Tu memineris sui cuiusque generis auctores diligenter eligere. Aiunt enim multum legendum esse, non multa. 16 Qui sint hi, adeo notum peruagatumque est, ut demonstratione non egeat; et alioqui tam immodice epistulam extendi, ut, dum tibi quemadmodum studere debeas suadeo, studendi tempus abstulerim. Quin ergo pugillares resumis et aliquid ex his uel istud ipsum quod coeperas scribis? Vale.

\section{Tradução}

\section{Saudações, meu caro Fusco.}

1 Tu me perguntas como deves estudar no isolamento que desfrutas já há um bom tempo. 2 Antes de tudo é útil, e muitos assim o recomendam, traduzir quer do grego para o latim quer do latim para o grego. ${ }^{16}$ Com esse gênero de exercício, adquire-se a propriedade e o esplendor das palavras,

\footnotetext{
${ }^{16}$ Quintiliano aconselha o mesmo (X.5, 2), citando, porém, como referências e autoridades que fundamentam a importância da tradução, Crasso (no De oratore de Cícero), Cícero e Messala. Plínio é mais sintético, mas, quando diz que "muitos recomendam" essa prática, com verossimilhança estaria se referindo a essas mesmas figuras, além obviamente do próprio Quintiliano. Outra diferença é que este dá maior ênfase à tradução do grego para o latim, diferentemente de Plínio, que considera a tarefa inversa igualmente relevante.
} 
a abundância das figuras (de estilo), a força de expressão; além disso, pela imitação dos melhores, a facilidade de engendrar coisas semelhantes às deles. ${ }^{17}$ Ao mesmo tempo, as nuances que poderiam escapar a quem lê não o podem a quem traduz. É dessa maneira que se adquirem o discernimento e o senso crítico. $3 \mathrm{Em}$ nada prejudicará que reescrevas, como um rival, o que já tiveres lido - a fim de reteres o assunto e o argumento -, e que compares o escrito com o lido e ponderes atentamente o que tenham - tu e ele - expressado mais apropriadamente. Grande será a alegria se tu o superares em algumas partes, grande a vergonha se ele te superar em tudo. Poderás também vez ou outra escolher textos bem conhecidos e competir com eles. ${ }^{18} 4$ Intento esse audaz, mas não impudente, uma vez que a disputa é secreta, embora vejamos muitos terem escolhido, com grande louvor, competições desse tipo e, enquanto se mantiveram confiantes, terem superado aqueles que consideravam suficiente apenas imitar. ${ }^{19} 5$ Poderás ainda retomar algum discurso que abandonaste,

${ }^{17}$ Compare-se com o que afirma Quintiliano em relação ao exercício de traduzir do grego para o latim: "A importância desse tipo de exercício intelectual é evidente. De fato, os autores gregos se distinguem pela grande variedade de assuntos e contribuíram muitíssimo para a arte da retórica; e traduzindo-os, é preciso empregar as melhores palavras; usemos, porém, nossas próprias palavras. Mas existe certa necessidade de criarmos muitas e diversificadas figuras, com que se ornamenta especificamente o discurso, porque a língua latina difere, sob esse aspecto, bastante da dos gregos." (Et manifesta est exercitationis huiusce ratio. Nam et rerum copia Graeci autores abundant et plurimum artis in eloquentiam intulerunt, e hos transferentibus verbis uti optimis licet, omnibus enim utimur nostris. Figuras vero quibus máxime ornatur oratio, multas ac varias excogitandi etiam necessitas quaedam est, quia plerumque a Graecis Romana dissentiunt $)(X .5,3)$. Pela comparação é possível notar que Plínio enxergava benefícios extras na tarefa de tradução, como o desenvolvimento do senso crítico (iudicium).

${ }^{18}$ Recomenda-se que Fusco, como um êmulo (aemulus) ou "competidor", crie paráfrases dos textos que leu, que devem ser sempre aqueles produzidos pelos melhores autores. Seria uma espécie de competição saudável com o texto original, um verdadeiro exercício de equivalência ou superação de suas qualidades mais evidentes. O objetivo seria o desenvolvimento das habilidades de escrita pela imitação do que havia de melhor em termos de produção textual à época. Quintiliano também recomendava a paráfrase competitiva: "não quero que a paráfrase seja apenas uma interpretação, mas que haja disputa e emulação em relação aos significados." (Neque ego paraphrasim esse interpretationem tantum volo, sed circa eosdem sensos certamen atque aemlationem) $(\mathrm{X} .5,5)$

${ }^{19}$ A possibilidade de superação dos modelos já havia sido reconhecida por Quintiliano: "Aliás, nem sempre é preciso perder a esperança de poder encontrar algo melhor do que aquilo que foi dito; nem a natureza fez a eloquência tão vazia e pobre, a ponto de não ser possível expressar bem alguma coisa senão uma só vez." (Nam neque semper est desperandum, aliquid illis, quae dicta sunt, melius posse reperiri; neque adeo ieiunam ac pauperem natura eloquentiam fecit, ut una de re bene dici nisi semel non possit) (X.5, 5). 
conservar muitas coisas, desprezar outras tantas, entrelinhar umas, reescrever outras. $6 \mathrm{E}$ um trabalho penoso e extremamente entediante, mas frutífero em razão mesmo da própria dificuldade; é reaquecer e recuperar integralmente o ímpeto que se fragmentou e abandonou; enfim, é entrelaçar a um corpo já completo como que novos membros sem, contudo, perturbar os já existentes. ${ }^{20}$

7 Sei que teu principal interesse atualmente está na eloquência, mas não por isso te aconselharei um estilo sempre polêmico e por assim dizer belicoso. Com efeito, assim como os solos são cultivados com variadas e cambiantes sementes, nossas inteligências o são ora com este, ora com aquele exercício. 8 Desejo que de tempos em tempos seleciones algum episódio da história, ${ }^{21}$ e que escrevas cartas mais diligentemente; ${ }^{22}$ porque amiúde, mesmo em um discurso, ocorre a necessidade de descrições não só históricas, mas também quase poéticas, e de uma carta requer-se uma linguagem clara e concisa. 9 É lícito igualmente recrear-se

${ }^{20}$ Deve-se fazer a revisão daquilo que se escreveu e abandonou. O objetivo é conservar (retinere) o que estiver bom e conveniente; suprimir (transire) o que dentro do texto for supérfluo, excessivo, inadequado, e reescrever (rescribere) o que se julgar ruim e incorreto. A importância desse exercício é bastante exaltada por Quintiliano: "Em seguida vem a correção, parte dos estudos sumamente útil. Pois não sem motivo se acredita que não se aprimora mais a arte de escrever quando se apaga. Contudo, a tarefa deste trabalho é acrescentar, suprimir e alterar. Nesses casos, é mais fácil e mais simples a decisão sobre o que deve ser completado ou cortado, em um duplo empenho de reduzir os inchaços, destacar os pontos merecedores de mais destaque, restringir os exageros, reorganizar as digressões, recompor as partes soltas e limitar o excesso de exultação. Assim, por exemplo, urge condenar aquilo que previamente nos agradou e descobrir os aspectos que nos escaparam." (Sequitur emendatio, pars studiorum longe utilíssima. Neque enim sine causa creditum est stilum non minus agere, cum delet. Huius autem operis est adiicere, detrahere, mutare. Sed facilius in iis simpliciusque iudicium, quae replenda vel deicienda sunt; premere vero tumentia, humilia extollere, luxuriantia adstringere, inordinata digerere, soluta componere, exultantia coercere, duplicis operae. Nam et damnanda sunt quae placuerunt et invenienda quae fugerant $)(\mathrm{X} .4,1)$

${ }^{21}$ O objetivo seria munir o discurso com referenciais históricos louváveis e reconhecíveis pelos interlocutores com vistas a ampliar o poder persuasivo das palavras do orador. Quintiliano via nessa técnica também uma forma de exercitar a invenção e a disposição do assunto. De maneira que "a riqueza da história deve ser por vezes inserida em alguma parte de tais exercícios e assim podermos desfrutar da liberdade dos diálogos." (historiae nonnunquam ubertas in aliqua exercendi stili parte ponenda et dialogorum libertate gestiendum $)(\mathrm{X} .5,16)$

${ }^{22}$ É um exercício de concisão, correção e sobriedade. 
compondo-se poemas; não digo contínuos e longos (pois isso não se pode realizar a não ser no ócio), mas engenhosos e breves (que sejam agradáveis e deem pausa às ocupações e preocupações, quantas forem) 10 São chamados de "passatempos", porém, alcançam algumas vezes uma glória não menor que a de coisas sérias. Assim sendo (por que não te encorajo com versos a fazer versos?)

11 Como é orgulho para a cera, mole e maleável, obedecer aos hábeis dedos e produzir a obra ordenada, e ora dar forma a Marte ou à casta Minerva, ora representar Vênus, ora o filho de Vênus; e como as fontes sagradas, que não detêm só incêndios, mas amiúde também auxiliam as flores e os prados vernais, assim convém que o engenho humano, com douta mobilidade, modele-se e guie-se por saberes flexíveis.

12 Por isso os maiores oradores, os maiores homens assim se exercitavam ou se deleitavam, ou melhor, se deleitavam e se exercitavam. 13 De fato é surpreendente como o espírito se expande e repousa com esses breves escritos. Eles incorporam os amores, os ódios, as cóleras, a compaixão, os gracejos, em suma, tudo que se encontra (habitualmente) na vida, e também no foro e nas causas. 14 Além disso, apresentam a mesma vantagem que os outros poemas porque, depois de submetidos às exigências métricas, regozijamo-nos com as liberdades da prosa e com maior prazer escrevemos aquilo que a comparação nos mostra ser mais fácil. ${ }^{23}$

15 Tens talvez mais do que pedias, entretanto omiti uma coisa: eu não te disse oque considero que devas ler; embora o tenha dito quando teaconselhei o que deverias escrever. Lembra de escolher tu mesmo, cuidadosamente, os autores de cada gênero. Diz-se com efeito que se deve ler muito, não muitos. 16 Quais sejam esses é algo tão conhecido e divulgado que

\footnotetext{
${ }^{23}$ Como vimos, Plínio confere grande relevância ao exercício de composição de poemas. Além de uma recreação que amenizaria as preocupações do dia a dia, os poemas seriam uma versão minimalista das circunstâncias da vida, e ao compô-los, o orador ou o advogado estaria igualmente exercitando e amplificando sua relação com os temas e os contextos que invariavelmente surgem em sua prática cotidiana. Para Quintiliano, da mesma forma, esse exercício é uma pausa ao rigor dos embates no foro e nos tribunais, "assim como os atletas que, deixando de lado, por certos períodos, a abstenção de determinados alimentos e dos treinos, se refazem com o lazer e iguarias saborosas." (sicut athletae, remissa quibusdam temporibus ciborum atque exercitationum certa necessitate, otio et iucundioribus epulis reficiuntur) $(\mathrm{X} .5,15)$.
} 
não carece de demonstração, ${ }^{24}$ além do que, já estendi tanto as dimensões desta carta que, enquanto te aconselho como devas estudar, eu te suprimi o tempo de estudo. Por que então não retomas as tabuinhas e escreves algo a partir do que te recomendei ou isso mesmo que tinhas iniciado? Adeus.

\section{Referências}

CICERO. Brutus. Translated by G. L. Hendrickson and H. M. Hubbell. Cambridge: Harvard University Press, 1939. DOI: https://doi.org/10.4159/ DLCL.marcus tullius cicero-brutus.1939.

CICERO. De oratore. Translated by E. W. Sutton. London: Harvard University Press, 1967.

DOMINIK, William J. The development of Roman rhetoric. In: MACDONALD, Michael J. (ed.). The Oxford handbook of rhetorical studies. Oxford: Oxford University Press, 2017. p. 159-171.

GÓMEZ, Leonor Pérez. La epístola en Roma: Siglos II-IV. In: CODOÑER, Carmen (ed.). Historia de la Literatura Latina. Madrid: Catedra, 1997. p. 653-664.

MOMMSEN, Theodor. Étude sur Pline le Jeune. Traduit par C. Morel. Paris: Librairie A. Franck, 1873.

PEREIRA, Maria Helena da Rocha. Estudos de História da Cultura Clássica: cultura romana. 2. ed. Lisboa: Fundação Calouste Gulbenkian, 1990.

PLINE, Le Jeune. Lettres. Texte établi et traduit par Anne-Marie Guillemin. Paris: Les Belles Lettres, 2002.

PLÍNIO, o Jovem. In: ENCICLOPEDIA Treccani. Roma: Istituto della Enciclopedia Italiana, [20--?]. Disponível em: https://www.treccani.it/ enciclopedia/plinio-il-giovane. Acesso em: 15 jan. 2021.

\footnotetext{
${ }^{24}$ Recomenda, portanto, a leitura dos melhores autores (optimi). Essa lista, de acordo com Plínio, seria à época já bastante vulgarizada, e não incorreríamos em erro supor que Plínio se referisse à relação de autores e obras que seu mestre, Quintiliano, apresenta na Instituição Oratória (X.1). Abrange autores gregos e latinos das diversas áreas do conhecimento. Seriam os optimi da história (Tucídides, Heródoto, César, Salústio etc.), da literatura (Homero, Hesíodo, Aristófanes, Lucrécio, Virgílio etc.), da filosofia (Xenofonte, Platão, Aristóteles etc.), da eloquência (Demóstenes, Cícero etc.) dentre outras áreas.
} 
PLINY. Natural History, Vol. VII: Books 24-27. Translated by W. H. S. Jones. Cambridge: Harvard University Press, 1956.

QUINTILIANO. Instituição Oratória. Trad. Bruno Fregni Bassetto. Campinas: Editora da Unicamp, 2016. $4 \mathrm{v}$.

SHERWIN-WHITE, A. N. The Letters of Pliny: A Historical and Social Commentary. Oxford: Clarendon Press, 1985.

VASCONCELOS, Beatriz Avila. Quatro princípios de educação oratória segundo Quintiliano. Phaos, n. 2, 2002, p. 205-225.

WHITTON, Christopher. The Arts of Imitation in Latin Prose: Pliny's Epistles/Quintilian in Brief. London: Cambridge University Press, 2019. DOI: https://doi.org/10.1017/9781108688550.

Recebido em: $1^{\circ}$ de fevereiro de 2021. Aprovado em: 6 de abril de 2021. 